\title{
Relationship of Circulating Tumor Necrosis Factor Alpha (TNF-a) and Insulin Secretion and Resistance in Euglycaemic Dogs
}

\author{
Ivana Lakić, Branislava Belić, Marko Cincović, Aleksandar Potkonjak, Dragiša Trailović \& Zorana Kovačević
}

\begin{abstract}
Background: Insulin resistance is a state that is characterized with reduced sensitivity of peripheral tissues to insulin. It can be related with increased level of tumor necrosis factor alpha (TNF- $\alpha$ ) in dogs. Insulin resistance can be evaluated by homeostasis model assessment (HOMA-IR, HOMA- $\beta$ ). The aim of this study was to determine correlation of circulating TNF- $\alpha$ level with insulin production and insulin resistance indexes in euglycaemic dogs.

Materials, Methods \& Results: Seventy dogs of normal body score were included in this study. After blood sampling levels of glucose, insulin and TNF- $\alpha$ were determined and indexes HOMA-IR and HOMA- $\beta$ were calculated. Three groups in accordance to TNF- $\alpha$ levels were formed: the first-TNF- $\alpha$ 0-2.0 pg/mL, the second-TNF- $\alpha$ below median $(2.1-17.0 \mathrm{pg} / \mathrm{mL})$ and the third-TNF- $\alpha$ above median (17.1-51.8 pg/mL). Differences in insulin and glucose levels, HOMA-IR and HOMA- $\beta$ were determined in all three groups. ANOVA and posthock LSD analyses were used. Correlation between HOMA-IR and HOMA- $\beta$ was determined. Linear regression between HOMA- $\beta$ /HOMA-IR ratio and glucose concentration was calculated. SPSS statistical program was used (IBM). Highest insulin level was detected in the second group and the lowest was detected in the third group. The lowest glucose level was detected in the first group. The highest value of HOMA- $\beta$ index was noted in the first group and it decreases with TNF- $\alpha$ increase. The highest HOMA-IR value was detected in the second group and the lowest was in the third group. Positive correlation was noted between HOMA-IR and HOMA- $\beta$. Significant linear correlation was noted between glucose levels in function of HOMA- $\beta / \mathrm{HOMA}-\mathrm{IR}(\mathrm{R} 2=0.51-0.78, P=0.0007)$. The first group showed the minor change of glucose level $(b=0.29 \mathrm{mmol} / \mathrm{L})$. In the third group the greatest change of glucose level in function of HOMA- $\beta /$ HOMA-IR was noted $(b=0.52 \mathrm{mmol} / \mathrm{L})$. In the third group the highest increase of glucose level followed by decrease in HOMA- $\beta /$ HOMA-IR ratio was noted.

Discussion: Increase of TNF- $\alpha$ followed by increase of insulin was noted in the second group. That indicates reduced insulin action and compensatory increase in his concentrations in order to achieve the same effect. TNF- $\alpha$ induces reduction in expression of glucose transporter 4 that is insulin-regulating hormone. Serine phosphorylation of insulin receptor substrate- 1 that is induced by TNF- $\alpha$ causes inhibition of insulin receptors. These actions cause insulin resistance and compensatory increase in insulin secretion. Increased tissue resistance is reflected in increased HOMA-IR index which is directly associated with insulin and glucose level. Increase of insulin value and HOMA-IR index were noted in second group. This indicates the influence of TNF- $\alpha$ on insulin resistance. The lowest insulin level was noted in the third group of dogs. Decrease in production and secretion leads to reduction in circulating insulin and can be evaluated by HOMA- $\beta$ index. The highest value of this index was noted in first group and decreases with TNF- $\alpha$ increase. This can be related with apoptotic effect that TNF- $\alpha$ has on beta- pancreatic cells. Increase of HOMA- $\beta$ index causes increase of HOMA-IR. This is indication of increased peripheral resistance. Compensatory mechanism for that state is increased insulin secretion. Glucose level will increase more during increase of HOMA-IR and decrease of HOMA- $\beta$. This indicates that TNF- $\alpha$ regulates glucose level directly and explains differences in glucose concentrations in dogs with different concentrations of TNF- $\alpha$ showed. Values of insulin resistance indexes, glucose and insulin were affected by circulating concentration of TNF- $\alpha$. The most unfavorable change in glucose concentration based on insulin production and tissue resistance was founded in dogs with the highest circulating TNF- $\alpha$ concentration in blood.
\end{abstract}

Keywords: dogs, insulin resistance, HOMA, TNF- $\alpha$.

DOI: $10.22456 / 1679-9216.100400$

Received: 9 January 2020

Accepted: 6 May 2020

Published: 23 May 2020

Laboratory of Pathophysiology, Department of Veterinary Medicine, Faculty of Agriculture, University of Novi Sad, Novi Sad, Serbia. CORRESPONDENCE: M. Cincović [mcincovic@ gmail.com]. Faculty of Veterinary Medicine, University of Belgrade. Bulevar Oslobođenja n. 18. ZC 11000 Belgrade, Serbia. 


\section{INTRODUCTION}

Insulin resistance (IR) is a state of reduced sensitivity of peripheral tissues to circulating insulin. In order to improve insulin sensitivity in peripheral tissues organism requires higher insulin levels to regulate the same levels of glucose. In the state of resistance insulin levels can be normal, higher or reduced $[4,19,34,32]$. IR can be evaluated by indexes of insulin resistance [17,3]. Homeostasis model assessment (HOMA) is often used in clinical trials. This model evaluates the capacity of pancreatic beta cells to secrete insulin (HOMA- $\beta$ ) and values resistance of peripheral tissue to insulin (HOMA-IR) [29]. There are some limitations when HOMA is used on dog models [1] but it is performed from golden standard for evaluation of insulin IR so it's very significant [17].

IR is influenced by glycolipotoxic state, reactive oxygen species production, epigenetic factors etc. Increased levels of proinflammatory cytokines and chronic inflammation have significant influence on IR development [16]. Pathogenesis of this syndrome hasn't been fully understood, but it has been considered that mild inflammation has the crucial role. Experimental, clinical and epidemiological studies showed that proinflammatory cytokine levels, including tumor necrosis factor- $\alpha$ (TNF- $\alpha$ ) are significantly higher in animals with IR and diabetes mellitus type II. This indicates crucial role of TNF- $\alpha$ in development of IR $[2,5,9,21]$. Many other experiments have been conducted in order to study the influence of TNF- $\alpha$ on IR in humans [3,10,14,18,23,32] and animals [11,12,27].

This study aims to examine correlation of circulating TNF- $\alpha$ with indexes of insulin resistance in euglycaemic dogs.

\section{MATERIALS AND METHODS}

\section{Animals and laboratory analysis}

Seventy dogs were included in this experiment. Research was conducted at Veterinary Clinic and Laboratory for pathophysiology, Department of Veterinary medicine (University of Novi Sad). Concentrations of TNF- $\alpha$ were determined and thereafter three groups were formed. First group: $50 \mathrm{dogs}$ that have no detectable TNF- $\alpha$ concentrations $(0-2.0 \mathrm{pg} /$ $\mathrm{mL})$. Second group: 10 dogs that have TNF- $\alpha$ concentrations below the median $(2.1-17.0 \mathrm{pg} / \mathrm{mL})$. Third group: 10 dogs that have TNF- $\alpha$ concentration above the median (17.1-51.8 $\mathrm{pg} / \mathrm{mL})$. Blood samples were taken from $v$. cephalica in tubes that contained clot activator. Glucose concentration was determined by automatic biochemical analyzer Rayto Chemray 120 Vet $^{1}$. Glucose level was determined after its enzymatic oxidation in presence of glucose-oxidase. Obtained hydrogen peroxide from previous reaction further reacts with 4-amino-phenazine and phenol in presence of catalytic peroxidase. Red-purple color was obtained and its intensity was measured. Insulin concentration determination was conducted at endocrinological analyzer Tosoh AIA- $360^{2}$ using immunofluorescence method. Concentration of tumor necrosis factor alpha was determined simultaneously at all samples after their thawing. Canine TNF alpha ELISA ${ }^{3}$ kit was used. Color intensity was measured by ELISA Rayto 2100C microplate reader $450 \mathrm{~nm}$. Optical densities were converted into $\mathrm{pg} / \mathrm{mL}$. Lower detection limit of this ELISA plate was $2 \mathrm{pg} / \mathrm{mL}$.

HOMA-IR index was calculated according to the formula: [glucose $(\mathrm{mmol} / \mathrm{mL}) \times$ insulin $(\mu \mathrm{IU} / \mathrm{mL})$ ]/ 22,5 and HOMA- $\beta$ : $20 \times$ insulin $(\mu \mathrm{IU} / \mathrm{mL}) /$ glucose (mmol/mL)-3.5.

\section{Statistical analysis}

Differences in insulin concentration, glucose concentrations, HOMA-IR and HOMA- $\beta$ were determined in all groups of dogs. ANOVA and posthock LSD analyses were used. Correlation between HOMAIR and HOMA- $\beta$ was determined. Linear regression between value of quotient of these two indexes and glucose concentration was calculated in all three groups of animals. SPSS statistical program was used (IBM) ${ }^{4}$.

\section{RESULTS}

Insulin resistance indexes, insulin and glucose concentrations were significantly affected by concentration of circulating TNF- $\alpha$ concentration. Highest insulin concentration was detected in group of dogs with TNF- $\alpha$ concentration below the median, while lowest concentration of insulin was detected in group with TNF- $\alpha$ concentration above the median. Group of dogs with undetectable TNF- $\alpha$ was between these two groups (Figure 1).

The lowest glucose concentration was detected in first group and increases with TNF- $\alpha$ increase (Figure 2). The highest value of HOMA- $\beta$ index was noted in group of dogs that expressed undetectable TNF- $\alpha$ 
concentration and it decreases with TNF- $\alpha$ concentration increase (Figure 3).

The highest HOMA-IR value was detected in second group of dogs and the lowest was in the third group (Figure 4). Positive correlation was noted between HOMA-IR and HOMA- $\beta$ (Figure 5).

Significant linear correlation was noted between change in glucose concentrations in function of HOMA- $\beta$ /HOMA-IR $\left(\mathrm{R}^{2}=0.51-0.78, P=0.0007\right)$. Change of glycaemia in function of HOMA- $\beta /$ HOMAIR in all three groups was showed in regression ana-

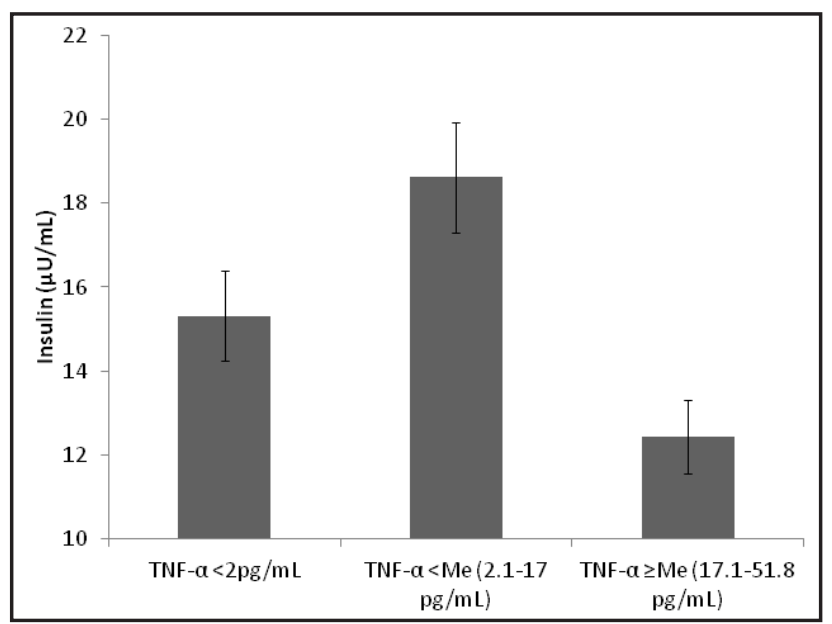

Figure 1. Insulin concentrations according to TNF- $\alpha$ concentration.

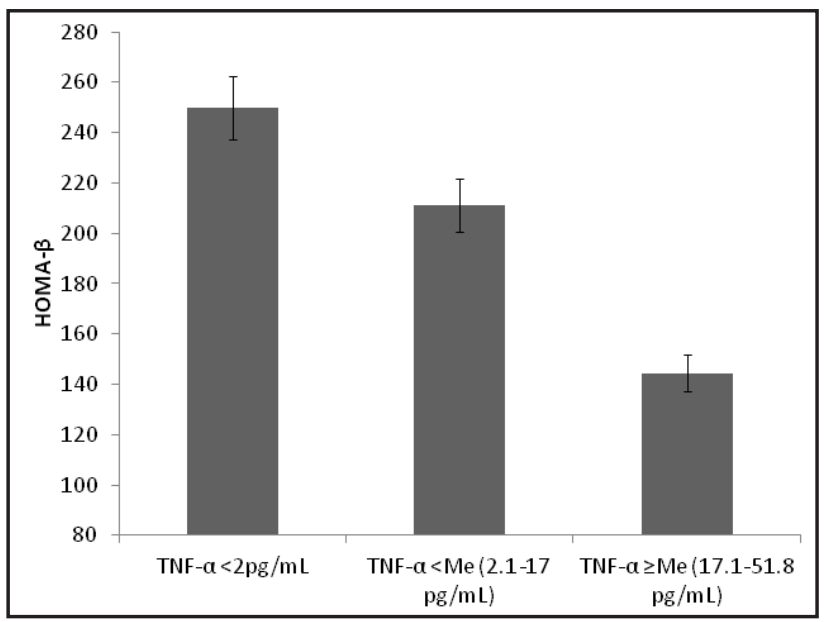

Figure 3. HOMA- $\beta$ index value according to TNF- $\alpha$ concentration.

\section{DISCUSSION}

Increase of TNF- $\alpha$ followed by increase of insulin concentration was noted in the second group of animals that expressed TNF- $\alpha$ concentrations below the median. That indicates reduced insulin action and compensatory increase in his concentrations in order to achieve the same effect. This cytokine has a crucial role in development lyze- group of dogs with undetectable TNF- $\alpha$ showed the minor change of glucose concentrations $(b=0.29$ $\mathrm{mmol} / \mathrm{L})$.

In the group with TNF- $\alpha$ above the median greatest change of glucose concentration in function of HOMA- $\beta /$ HOMA-IR was noted $(b=0.52 \mathrm{mmol} / \mathrm{L})$. Second group was between them $(b=0.29 \mathrm{mmol} / \mathrm{L})$. In group of dogs with highest TNF- $\alpha$ concentration highest increase of glucose concentration followed by decrease in HOMA- $\beta$ /HOMA-IR ratio was noted (Figure 6).

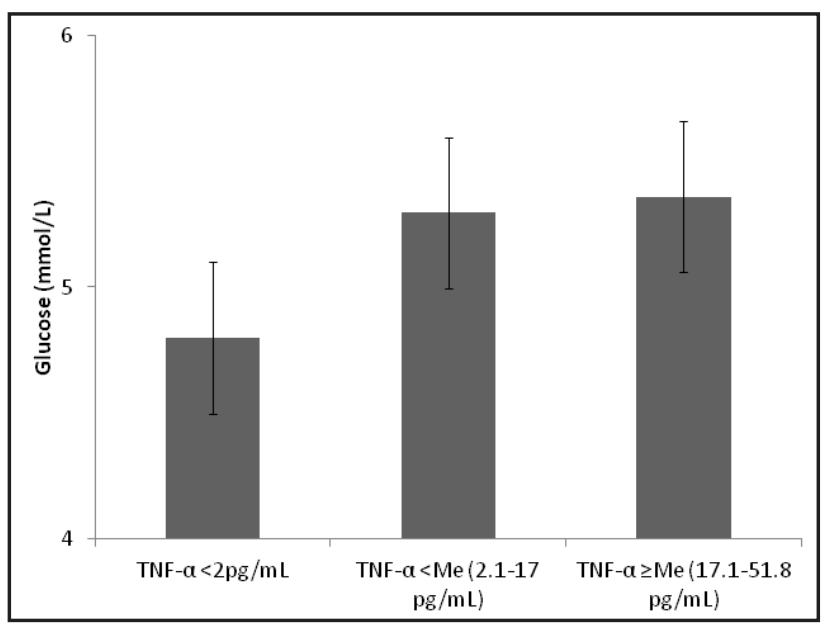

Figure 2. Glucose concentrations according to TNF- $\alpha$ concentration.

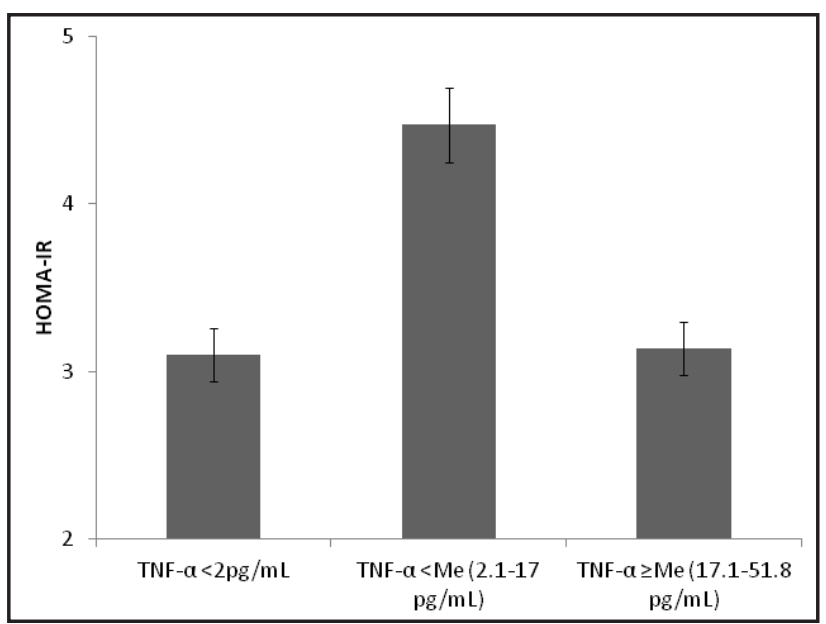

Figure 4. HOMA-IR values according to TNF- $\alpha$ concentration.

of insulin resistance [2]. TNF- $\alpha$ induces reduction in expression of glucose transporter 4 (GLUT 4) which is insulin-regulating hormone in adipocytes, skeletal muscles and cardiac myocytes. Serine phosphorylation of insulin receptor substrate-1 (IRS-1) that is induced by TNF- $\alpha$ causes inhibition of insulin receptors and reduces activity of phosphatidylinositol-3 kinase. These actions cause insulin resistance and compensatory increase in insulin secretion. 


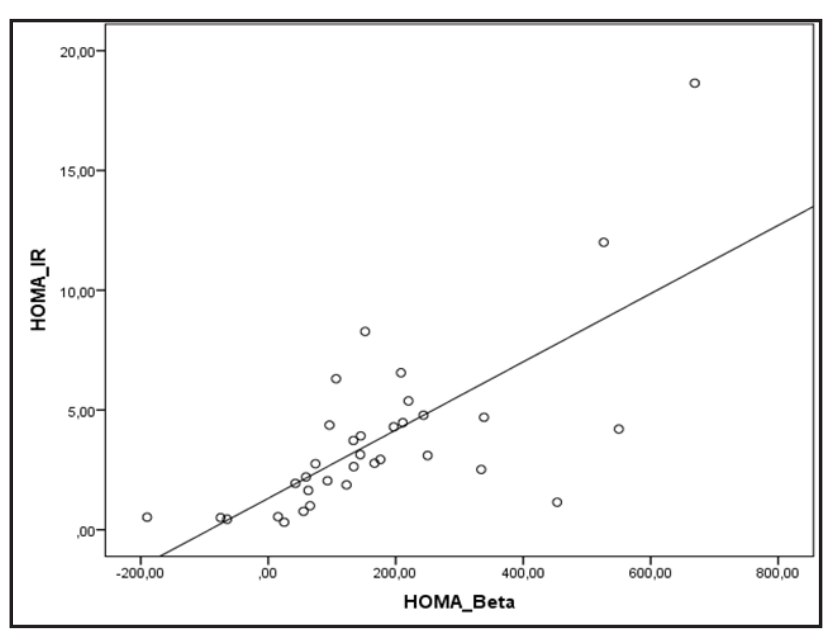

Figure 5. Correlation matrix of HOMA- $\beta$ and HOMA-IR.

Stanley et al. [25] and Dong et al. [8] showed impaired insulin action on animal models and/or cell cultures that contained TNF- $\alpha$ receptors compared to animal models and/or cell cultures that lacked TNF- $\alpha$ receptors. That indicates the great importance of TNF- $\alpha$ in development of insulin resistance. Increase in HOMA-IR index was noted in our second group of animals (TNF- $\alpha$ below the median). This index is directly dependent of glucose and insulin concentration, and increase in this index suggests greater peripheral tissue resistance to circulating insulin. Values of HOMA-IR have been studied in patients suffering from rheumatoid arthritis, and found significant positive correlation between HOMA-IR and TNF- $\alpha$ concentration [24]. Our results are in accordance with theirs. Blocking the TNF- $\alpha$ activity they significantly reduced HOMA-IR index and increased sensitivity of peripheral tissues to insulin. Gayet et al. [11] in their study on dogs have been concluded that obese dogs have significantly higher TNF- $\alpha$ concentration that is related with increase in insulin concentration and development of insulin resistance. Our results are in accordance with previous research.

The lowest insulin concentration was noted in third group of dogs. Decrease in production and secretion leads to reduction in circulating insulin. That is represented in reduced HOMA- $\beta$ insulin resistance index. HOMA- $\beta$ shows secretory capacity of beta-pancreatic cells. The highest value of this index was noted in first group of dogs and decreases with TNF- $\alpha$ increase. So, the lowest value of HOMA- $\beta$ was noted in the third group of dogs. This indicates

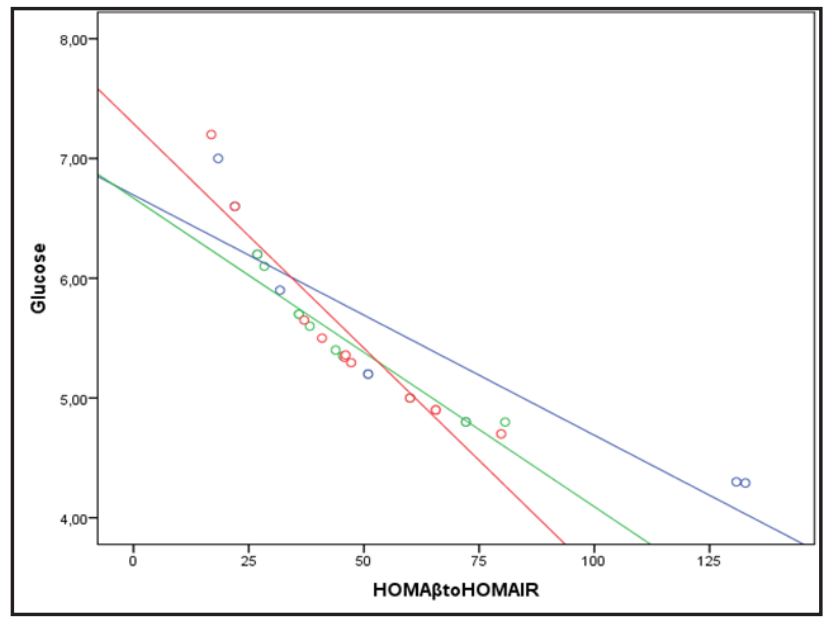

Figure 6. Correlation of HOMA- $\beta$ / HOMA-IR ratio and glucose concentrations in experimental groups of dogs. Red line: TNF- $\alpha>$ Me; Green line: TNF- $\alpha<\mathrm{Me}$; Blue line: TNF- $\alpha$ undetectable concentration.

reduced secretory capacity of beta-pancreatic cells during TNF- $\alpha$ concentration increase. Reduced secretion can be caused by apoptosis of cells induced by TNF- $\alpha$. Studies that observed human patients and animal models with diabetes mellitus type I (DM1) have been investigating apoptotic capacity of TNF- $\alpha$ [28,31]. Similarities have been observed in human patients with diabetes mellitus type II (DM2) but pathophysiologic mechanisms in these two states are different. Initial phase of DM2 is characterized by normal or increased insulin production that should compensate insulin resistance in peripheral tissue. Further progression of disease and many factors, including cytokines can cause inflammation and damage of pancreatic islands. Inflammation and destruction of beta- cells is reflected in their reduced secretory capacity and reduced mass [6]. Increase in free fatty acids (FFA) concentration contributes to progression of that process. Free fatty acids express lipo-toxic effects on beta-pancreatic cells [6,22]. Cytokine action and combined cytokines and lipids action cause activation of reactive oxygen species (ROS) that can induce activation of caspases, reduction of betapancreatic cells secretion and progression of their apoptosis [31]. Pancreatic cells of rats reduce their secretory capability after treatment of interleukin 1-beta (IL-1 $\beta$ ) [28]. Apoptotic effect was even more pronounced when cells have been treated with combination of IL- $1 \beta$ and TNF- $\alpha$. Long term exposure of beta-pancreatic cells to TNF- $\alpha$ leads to their reduced secretory capacity [34]. Reduced HOMA- $\beta$ value was noted in second group compared to the first group 
in our research. But the lowest HOMA- $\beta$ value was noted in the third group of dogs with the highest concentrations of TNF- $\alpha$. This result can indicate progressive reduction of beta-pancreatic cells function caused by TNF- $\alpha$ and other factors.

Increase of HOMA- $\beta$ index causes increase of HOMA-IR [Figure 6]. This is indication of increased peripheral insulin resistance and compensatory mechanism for that state is increased insulin secretion in order to maintain normoglycaemia. That is in accordance with general concepts of insulin resistance. HOMA-IR increases while HOMA- $\beta$ decreases during insulin resistance and diabetes. That represents their inverse effects [23]. Glucose concentration will increase more during increase of HOMA-IR and decrease of HOMA- $\beta$. Dogs with highest TNF- $\alpha$ concentration represent this. Application of inhibitors and antibodies against TNF- $\alpha$ cause improvement in glucose concentrations and decrease risk of diabetes development $[25,33]$. This proposed that $\mathrm{TNF}-\alpha$ regulates glucose concentrations directly and explains differences in glucose concentrations in dogs with different concentrations of TNF- $\alpha$ showed in our results.

\section{CONCLUSION}

Based on everything listed it can be concluded that circulating TNF- $\alpha$ can affect all aspects of insulin resistance- insulin production and resistance in peripheral tissues in euglycaemic dogs. A change in glucose concentration in function of insulin production and peripheral resistance ratio is the most unfavorable in dogs with high concentrations of circulating TNF- $\alpha$ in blood. That confirms that this cytokine can control glycaemia by its own independently of degree of insulin resistance in dogs.

\section{MANUFACTURERS}

${ }^{1}$ Rayto Life and Analytical Sciences Co. Shenzhen, China.

${ }^{2}$ Tosoh Corporation, Scientific Instruments Division. Kaiseicho, Japan. ${ }^{3}$ Abcam Inc. Eugene, OR, USA.

${ }^{4} \mathrm{IBM}$ - International Business Machines Corporation. Armonk, NY, USA.

Acknowledgements. This research is supported by projects "Influence and clinical evaluation of blood serum tumor necrosis factor alpha (TNF- $\alpha)$ in inflammatory response of ruminants and dogs" - Provincial secretariat of high education and science, Vojvodina, Serbia.

Declaration of interest. The authors report no conflicts of interest. The authors alone are responsible for the content and writing of paper.

\section{REFERENCES}

1 Ader M., Stefanovski D., Richey J.M., Kim S.P., Kolka C.M., Ionut V., Kabir M. \& Bergman R.N. 2014. Failure of homeostatic model assessment of insulin resistance to detect marked diet-induced insulin resistance in dogs. Diabetes. 63(6): 1914-1919.

2 Akash M.S.H., Rehman K. \& Liaqat A. 2017. Tumor necrosis factor alpha: Role in development of insulin resistance and pathogenesis of type 2 diabetes mellitus. Journal of Cellular Biochemistry. 119(1): 105-110.

3 Borst S.E. 2004. The role of TNF- $\alpha$ in insulin resistance. Endocrine. 23(2-3): 177-185.

4 Cefalu W.T. 2001. Insulin resistance: cellular and clinical concepts. Experimental Biology and Medicine. 226(1): 13-26.

5 Chen L., Chen R., Wang H. \& Liang F. 2015. Mechanisms linking inflammation to insulin resistance. International Journal of Endocrinology. 2015. <https://doi.org/10.1155/2015/508409>.

6 Cieslak M., Wojtczak A. \& Cieslak M. 2015. Role of pro-inflamatory cytokines of pancreatic islets and prospects of elaboration of new methods for the diabetes treatment. Acta Biochemica Polonica. 62(1): 15-21.

7 Cincović M., Đoković R., Belić B., Lakić I., Stojanac N., Stevančević O. \& Staničkov N. 2018. Insulin resistance in cows during the periparturient period. Acta Agriculturae Serbica. 23(46): 233-245.

8 Dong Y., Dekens D.W., De Deyn P.P., Naudé P.J. \& Eisel U.L. 2015. Targeting of tumor necrosis factor alpha receptors as a therapeutic strategy for neurodegenerative disorders. Antibodies. 4(4): 369-408.

9 Ehses J.A., Lacraz G., Giroix M.H., Schmidlin F., Coulaud J., Kassis N., Irminger J.C., Kergoat M., Portha B., Homo-Delarche F. \& Donath M.Y. 2009. IL-1 antagonism reduces hyperglycemia and tissue inflammation in the type 2 diabetic GK rat. Proceedings of the National Academy of Sciences of the United States of America. 106(33): 13998-14003. 
10 Elochukwu A.C., Opara U.C., Chinyere N.A., Jeremiah O.S. \& Chukwuma O.O. 2017. Evaluation of tumor necrosis factor alpha, insulin and homeostasis model assessment of insulin resistance among obese participants living in Calabar, Nigeria. Tropical Journal of Medical Research. 20(1): 45-52.

11 Gayet C., Bailhache E., Dumon H., Martin L., Siliart B. \& Nguyen P. 2004. Insulin resistance and changes in plasma concentration of TNF $\alpha$, IGF1, and NEFA in dogs during weight gain and obesity. Journal of Animal Physiology and Animal Nutrition. 88(3-4): 157-165.

12 German A.J., Hervera M., Hunter L., Holden S.L., Morris P.J., Biourge V. \& Trayhurn P. 2009. Improvement in insulin resistance and reduction in plasma inflammatory adipokines after weight loss in obese dogs. Domestic Animal Endocrinology. 37(4): 214-226.

13 Gutch M., Kumar S., Razi S.M., Gupta K.K. \& Gupta A. 2015. Assessment of insulin sensitivity/resistance. Indian journal of endocrinology and metabolism. 19(1): 160-164.

14 Gwozdziewiczova S., Lichnovska R., Yahia R.B., Chlup R. \& Hrebicek J. 2005. TNF- $\alpha$ in the development of insulin resistance and other disorders in metabolic syndrome. Biomedical Papers. 149(1): 109-117.

15 Haffner S.M., Mykkanen L., Festa A., Burke J.P. \& Stern M.P. 2000. Insulin-resistant prediabetic subjects have more atherogenic risk factors than insulin-sensitive subjects: Implications for preventive coronary heart disease during the prediabetic state. Circulation. 101(9): 975-980.

16 Hamada D., Maynard R., Schott E., Drinkwater C.J., Ketz J.P., Kates S.L., Jonason J.H., Hilton M.J., Zuscik M.J. \& Mooney R.A. 2016. Suppressive Effects of Insulin on Tumor Necrosis Factor-Dependent Early Osteoarthritic Changes Associated with Obesity and Type 2 Diabetes Mellitus. Arthritis \& Rheumatology. 68(8): 1392-1402.

17 Hosker J.P., Matthews D.R., Rudenski A.S., Burnett M.A., Darling P., Bown E.G. \& Turner R.C. 1985. Continuous infusion of glucose with model assessment: measurement of insulin resistance and beta-cell function in man. Diabetologia. 28(7): 401-411.

18 Hossain M., Faruque M.O., Kabir G., Hassan N., Sikdar D., Nahar Q. \& Ali L. 2010. Association of TNF- $\alpha$ and IL-6 with insulin secretion and insulin resistance in IFG and IGT subjects in a Bangladeshi population. International Journal of Diabetes Mellitus. 2(3): 165-168.

19 Ibfelt T., Fischer C.P., Plomgaard P., van Hall G. \& Pedersen B.K. 2014. The acute effects of low dose TNF- $\alpha$ on glucose metabolism and $\beta$-cell function in humans. Mediators of Inflammation. 2014. http://dx.doi.org/10.1155/2014/295478.

20 Lasram M.M., Bouzid K., Douib I.B., Annabi A., El Elj N., El Fazaa S., Abdelmoula J. \& Gharbi N. 2015. Lipid metabolism disturbances contribute to insulin resistance and decrease insulin sensitivity by malathion exposure in Wistar rat. Drug and chemical toxicology. 38(2): 227-234.

21 Rehman K. \& Akash M.S. 2016. Mechanisms of inflammatory responses and development of insulin resistance: how are they interlinked? Journal of Biomedical Science. 23(1): 87.

22 Sharma R.B. \& Alonso L.C. 2014. Lipotoxicity in the pancreatic beta cell: not just survival and function, but proliferation as well? Current Diabetes Reports. 14(6): 492.

23 Song Y., Manson J.E., Tinker L., Howard B., Kuller L.H., Nathan L. \& Liu S. 2007. Insulin sensitivity and insulin secretion determined by homeostasis model assessment and risk of diabetes in a multiethnic cohort of women. Diabetes Care. 30(7): 1747-1752.

24 Stagakis I., Bertsias G., Karvounaris S., Kavousanaki M., Virla D., Raptopoulou A., Kardassis D., Boumpas D.T. \& Sidiropoulos P.I. 2012. Anti-tumor necrosis factor therapy improves insulin resistance, beta cell function and insulin signaling in active rheumatoid arthritis patients with high insulin resistance. Arthritis Research and Therapy. 14(3): R141.

25 Stanley T.L., Zanni M.V., Johnsen S., Rasheed S., Makimura H., Lee H., Khor V.K., Ahima R.S. \& Grinspoon S.K. 2011. TNF-alpha antagonism with etanercept decreases glucose and increases the proportion of high molecular weight adiponectin in obese subjects with features of the metabolic syndrome. The Journal of Clinical Endocrinology and Metabolism. 96(1): E146-150.

26 Vaccaro O., Masulli M., Cuomo V., Albarosa-Rivellese A., Uusitupa M., Vessby B., Hermansen K., Tapsell L. \& Riccardi G. 2004. Comparative Evaluation of Simple Indices of Insulin Resistance. Metabolism. 53(12): 1522-1526.

27 Verkest K.R., Rand J.S., Fleeman L.M. \& Morton J.M. 2012. Spontaneously obese dogs exhibit greater postprandial glucose, triglyceride, and insulin concentrations than lean dogs. Domestic Animal Endocrinology. 42(2): 103-112.

28 Wachlin G., Augstein P., Schoder D., Kuttler B., Kloting I., Heinke P. \& Schmidt S. 2003. IL-1beta, IFN-Gamma and TNFalpha increase vulnerability of pancreatic beta cells to autoimmune destruction. Journal of Autoimmunity. 20(4): 303-312. 
I. Lakić, B. Belić, M. Cincović, et al. 2020. Relationship of Circulating Tumor Necrosis Factor Alpha (TNF-a) and Insulin Secretion and Resistance in Euglycaemic Dogs. Acta Scientiae Veterinariae. 48: 1731.

29 Wallace T.M., Levy J.C. \& Matthews D.R. 2004. Use and abuse of HOMA modeling. Diabetes Care. 27(6): 14871495.

30 Walsh J.M., McGowan C.A., Byrne J.A., Rath A. \& McAuliffe F.M. 2013. The association between TNF- $\alpha$ and insulin resistance in euglycemic women. Cytokine. 64(1): 208-212.

31 Wang C., Guan Y. \& Yang J. 2010. Cytokines in the Progression of Pancreatic $\beta$-Cell Dysfunction. International Journal of Endocrinology. 2010. <https://doi.org/10.1155/2010/515136>.

32 Wilcox G. 2005. Insulin and Insulin Resistance. The Clinical Biochemist Review. 26(2): 19-39.

33 Yazdani-Biuki B., Stelzl H., Brezinschek H.P., Hermann J., Mueller T., Krippl P., Graninger V. \& Wascher T.C. 2004. Improvement of insulin sensitivity in insulin resistant subjects during prolonged treatment with the anti-TNFalpha antibody infliximab. European Journal of Clinical Investigation. 34(9): 641-642.

34 Zhang S. \& Kim K.H. 1995. TNF- $\alpha$ inhibits glucose-induced insulin secretion in a pancreatic -cell line (INS-1). FEBS Letters. 377(2): 237-239. 